$\left[\begin{array}{l}\text { Jpn. J. Hosp. Pharm. } \\ \frac{17(5)}{1706-311} \text { 論 } \\ \text { 3091) }\end{array}\right]$

\title{
片面圧縮法における割線入り錠剤の分割性に及ぼす 非平面の杵位亚の影響
}

\author{
伊東明彦，杉原正泰 \\ 東京女子医科大学病院薬剤部
}

\section{Effect of Position of Nonflat Punch on Dividing Properties of Scored Tablet in One Side Compaction Method}

\author{
AKiniko Ito, Masayasu Sugihara \\ Hospital Pharmacy, Tokyo Women's Medical College†
}

(Received April 23, 1991)

\begin{abstract}
The significance of the position of nonflat punch on dividing prcperties of scored tablets was investigated in several tablets prepared from excipients or granules by one side compaction method. For the excipients, lactose, perfiller ${ }^{\circledR}$ and microcrystalline cellulose were used. For the granules, sieved granules in 12-16, 16-32 and 32-48 mesh incorporating either hydroxy propyl cellulose or potato starch as binder was used.

Different influence of the position of nonflat punch on dividing strength of scored tablets was observed between the case of excipients and granules. Dividing strength of scored tablets made from excipients was not affected by the position of nonflat punch. But tablets made from granules had a tendency to show high dividing strength when tablets were compressed by nonflat upper punch. Then weight variation of divided tablets showed a tendency to become less when compressed by nonflat upper punch in both tablets made from excipients and granules. It was suggested that the effect of the position of nonflat punch on dividing properties of scored tablets was caused by different pressure lines during tablet compression.
\end{abstract}

Keywords — scored tablet; weight variation; dividing strength; nonflat punch; hydroxy propyl cellulose; potato starch; one side compaction method; excipient

粉体を圧縮する際，成形条件が得られた成形物 の物性に影響することはよく知られている．成形 条件のうち成形方法は種々あり，使用する粉体お よびその使用目的によって選択されている1．錠 剤を成形する場合，片面あるいは両面圧縮法が用 いられる．片面圧縮法は圧縮面の近くはよく充填 されるが反対面にいくにしたがって低密度にな

†東京都新宿区河田町8-1；8-1, Kawada-cho, Shinjuku-ku, Tokyo, 162 Japan
る. いわゆる高さ方向に対する密度分布の差を生 じる傾向があることが報告されている2). そのた め，片面圧縮法により割線入り錠剤を製する場 合, 非平面の杵の位置の違いによって錠剤の内部 構造は異なり，分割性に相違を生じることが考え られる．そこで片面圧縮法において非平面の杵の 位置が割線り錠剤の分割性に及ぼす影響について 検討した。 
Table 1. Physical Chracteristics of Test Samples

\begin{tabular}{lccccc}
\hline \hline \multicolumn{1}{c}{ Sample } & $\begin{array}{c}\text { Particle } \\
\text { Size } \\
\text { (mesh) }\end{array}$ & $\begin{array}{c}\mathrm{V}_{\mathrm{o}}^{*} \\
(\mathrm{ml} / \mathrm{g})\end{array}$ & $\begin{array}{c}\mathrm{V}_{\mathrm{t}}^{* *} \\
(\mathrm{ml} / \mathrm{g})\end{array}$ & $\mathrm{a}^{* * *}$ & \multicolumn{1}{c}{$1 / \mathrm{b}^{* * *}$} \\
\hline Lactose (SL) & $<100$ & 2.56 & 2.22 & 0.422 & 16.95 \\
Microcrystalline Cellulose (MCC) & $<100$ & 3.45 & 2.81 & 0.375 & 21.28 \\
Perfiller ${ }^{\circledR}$ & $<100$ & 2.53 & 2.18 & 0.201 & 14.93 \\
5\%HPC Gr. & $12 / 16$ & 2.13 & 2.09 & 0.101 & 111.11 \\
& $16 / 32$ & 2.17 & 2.11 & 0.094 & 71.43 \\
5\%Potato Starch Gr. & $32 / 48$ & 2.26 & 2.13 & 0.114 & 37.04 \\
& $12 / 16$ & 2.25 & 2.22 & 0.107 & 142.86 \\
& $16 / 32$ & 2.27 & 2.23 & 0.086 & 100.00 \\
& $32 / 48$ & 2.31 & 2.25 & 0.089 & 62.50 \\
\hline
\end{tabular}

\footnotetext{
* apparent specific volume before tapping.

** apparent specific volume after tapping (10 times).

*** Constant of Kawakita's equation of tapping compression.
}

\section{実䮎の 部}

\section{1. 試料}

実験に用いた粉末および湿式造粒した顆粒試料 をTable 1 亿示す. 粉末試料としては, 粉末乳糖 (SL, 日局), 結晶セルロース (MCC, 商品名ア ビセル®PH 101，旭化成）およびパーフィラー® （HPS を主体とする微細粒，フロイント産業）を それぞれ 100 メッュで節過したものを使用し た。また，顆粒試料としては，粉末乳糖（日局） とバレイショデンプン（日局）を $6: 4(\mathrm{w} / \mathrm{w}) の$ 割合で混合したものに結合剂としてヒドロキシプ ロピルセルロース (HPC, 日局) むしくはバレイ ショデンプン（日局）を $5 \%(\mathrm{w} / \mathrm{v})$ 水溶液とし て添加し，それぞれ破砕造粒法にて造粒後，12一 16，16一-32および32-48メッシュに分級したもの を使用した. いずれの試料についても滑沢剤とし て $0.5 \%(\mathrm{w} / \mathrm{w})$ の割合でステアリン酸マグネシ ウムを添加して打錠用の試料とした.

\section{2. 川北粉体圧縮式の定数の測定 ${ }^{3)}$}

Table 1 に示す $\mathbf{a}$ およ゙ $1 / \mathrm{b}$ は, タッピング圧 縮を行い川北のタッピング圧縮式より求めた。

$$
\mathrm{N} / \mathrm{C}=1 / \mathrm{ab}+\mathrm{N} / \mathrm{a}
$$

$\mathrm{C}$ は体積減少率, $\mathrm{N}$ はタッピング回数を示す.

\section{3. 錠唷の調製}

粉末試料は 1 錠重量として $300 \mathrm{mg}$ 秤量し, 成 形圧 $700 \mathrm{~kg} / \mathrm{cm}^{2}$, 顆粒試料は 1 錠重量として 400 $\mathrm{mg}$ を秤量し，成形圧 $1400 \mathrm{~kg} / \mathrm{cm}^{2}$ で $\mathrm{KBr}$ 錠剂 成形器にて, それぞれ 1 分間加圧し, 成形した。 割線の溝の深さは厚さの約10\%とした。

Fig. 1 に圧縮方法を模式的に示す. 非平面を上 杵とする方法を A 法, 非平面を下杵とする方法を B法とした。

\section{4. 分割方法及び錠剤の分割時の強度測定}

前報 ${ }^{4)}$ に準じ，レオメーターを用いて割線に沿 って分割し，その時の圧力を分割時の強度とし た。

\section{5. 分割後の重量の変動の測定}

前報 ${ }^{4)}$ の方法と同様に行った。

\section{結果および考察}

粉末試料を用いて，A法またはB法によって製 した錠凧の分割時の強度を Fig. 2 に示す.

いずれの試料についても圧縮方法の違いによる 差はほとんど認められなかった。また，いずれの 圧縮方法による場合も MCC が最も大きな強度を 示し, 次いでパーフィラー®で, SLが最も小さい 値を示した。これはそれぞれの成形性の違いによ るものと考える.

Fig. 3 に粉末試料を用いて，A法またはB 法 によって製した錠剤の分割重量の変動 $(\mathrm{CV})$ を示 す．MCCを用いた場合，圧縮方法の違いによる差 は認められなかったが，SLおよびパーフィラー® を用いた場合は， A法による錠剤が小さな $\mathrm{CV}$ 值 

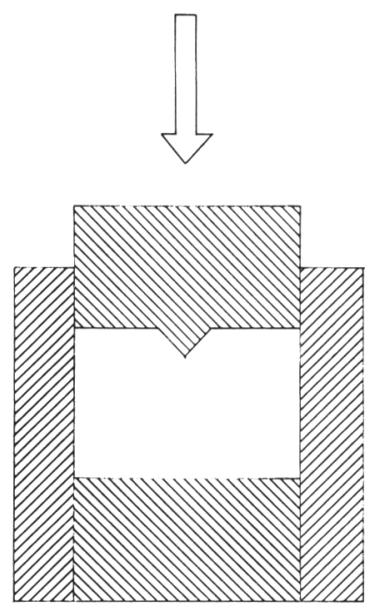

A-method
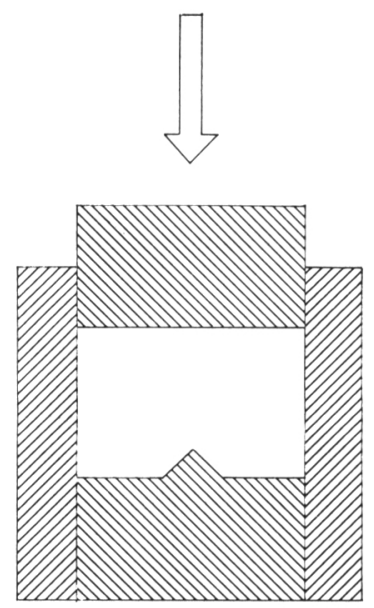

B-method

Fig. 1. Model of Compaction Method

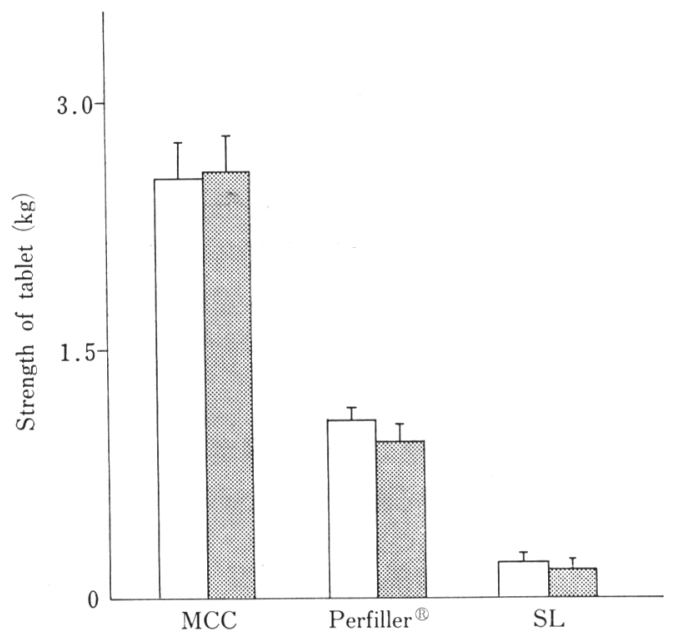

Fig. 2. Comparison of Strength of Tablet for Two Compaction Methods (Mean $\pm \mathrm{S}$. D., $\mathrm{n}=20$ )
: A-method,
: B-method

を示し，SLを用いた場合，圧縮方法の違いによ る差が大きく現われた。また，B法による錠剤で は, SL が最も大きな CV 值を示し, 次いでパー フィラー®で, MCC が最も小さな CV 值を示し た。そして，A法による錠剂では，SL が最も大 きな CV 值を示し,パーフィラー®および MCC はほどんど同様の值を示した。

Fig. 2 および Fig. 3 より, 試料間において,

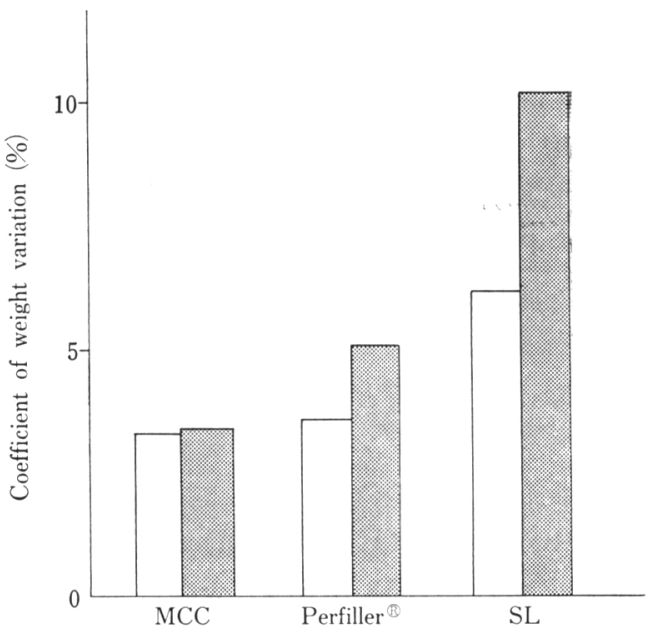

Fig. 3. Comparison of Weight Variation of Tablet Halves for Two Compaction Methods

$$
\text { : A-method, : : B-method }
$$

分割時の強度が大きな錠剂汪ど, より均一な分割 性を示す傾向が認められた。そして，その傾向は A法によるよりも B 法による場合に大きく現われ た。

顆粒試料を用いて，A法またはB 法により製し た錠剤の分割時の強度を, 打錠用顆粒の粒径毎に 2 種類の異なる結合剂を使用した場合について Fig. 4 亿示す. 

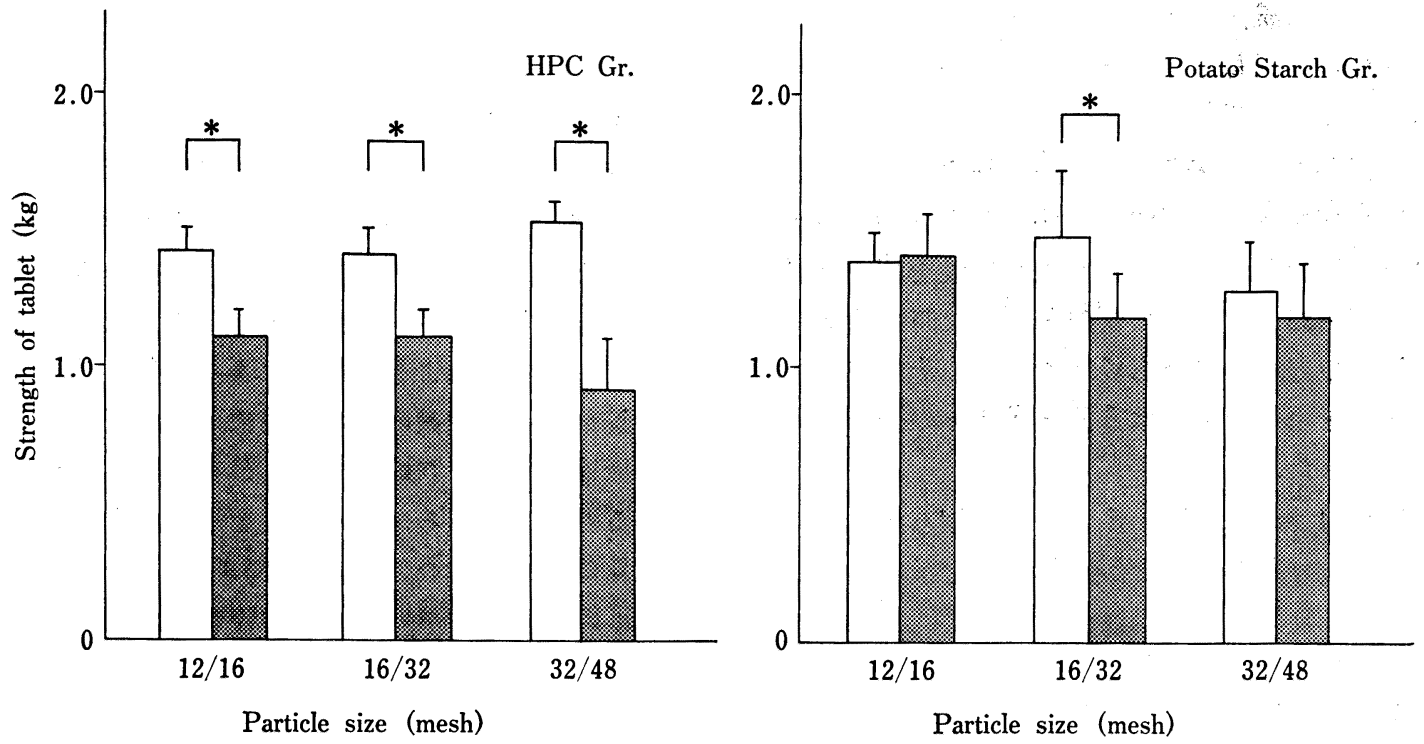

Fig. 4. Comparison of Strength (Mean \pm S.D., $\mathrm{n}=20$ )

: A-method, : B-method $* \mathrm{p}<0.05$
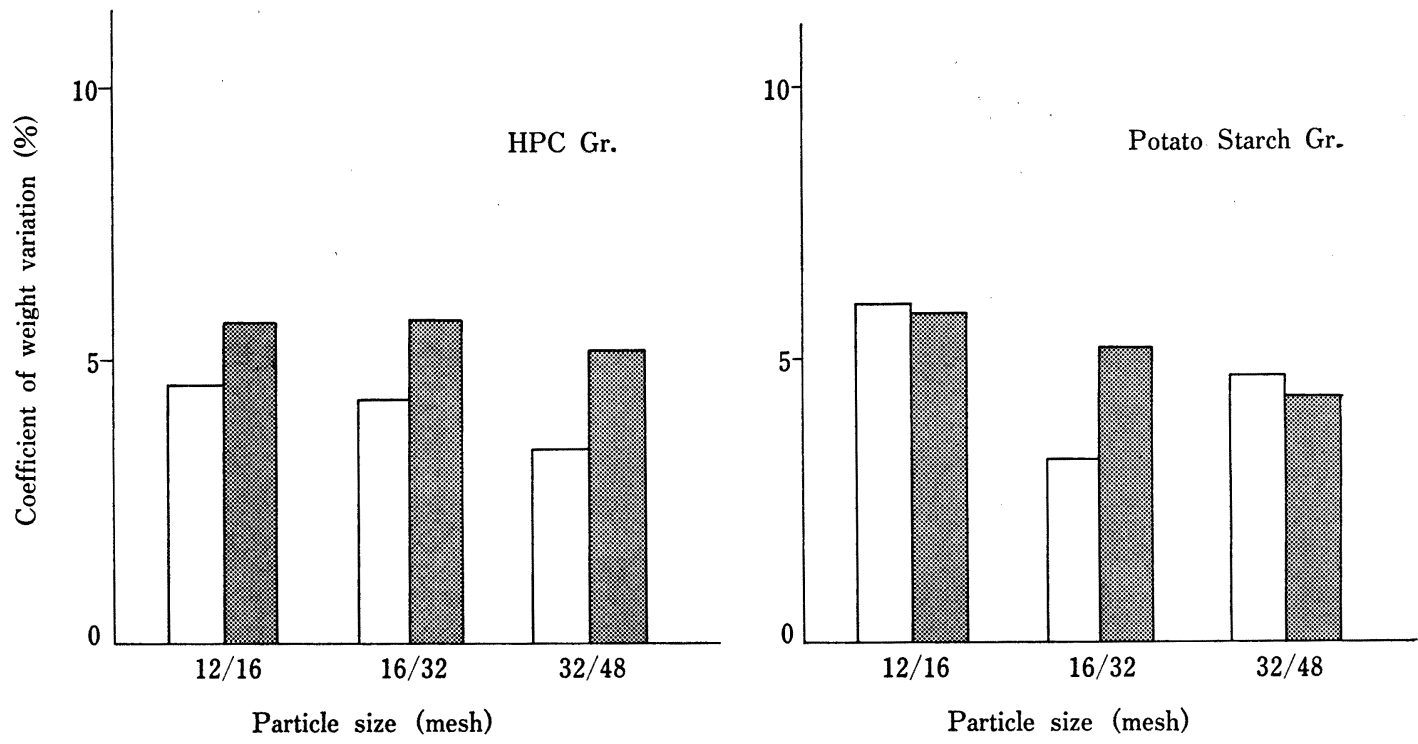

Fig. 5. Comparison of Weight Variation of Tablet Halves for Two Compaction Methods
: A-method,
: B-method

結合剤として HPC を使用した場合，いずれの 粒径の顆粒を用いた時もA法による錠剂の方が分 割時に大きな強度を示した。デンプン糊液を用い た場合は，16一32メッシュの顆粒を用いた時にA
法による錠剤の方が大きな值を示し，その他の粒 径の顆粒を用いた時には A法とB法との差は認め られなかった。

Fig. 5 に顆粒試料を用いて，A法またはB法に 
より製した錠剤の分割重量の変動 $(\mathrm{CV})$ を，打錠 用顆粒の粒径毎に 2 種類の異なる結合剂を使用し た場合について示す.

結合剂として HPC を使用した場合，いずれの 粒径の顆粒を用いた時もA法による錠剤の方が小 さな $\mathrm{CV}$ 值を示した.デンプン糊液を用いた場合 は，16一32メッシュの顆粒を用いた時にA法によ る錠剤の方が小さな CV 值を示し，その他の粒径 の顆粒を用いた時にはA法とB法との差は認めら れなかった。

Fig. 4 および Fig. 5 より，圧縮方法の違いに おいて，分割時の強度が大きな值を示した錠剤の 方が，より均一な分割性を示した。

以上のように，分割時の強度は粉末試料を用い た場合と顆粒試料を用いた場合で異なった傾向を 示した，粉末試料を用いた場合，非平面の杵の位 置の違いによる差は認められなかったが，顆粒試 料を用いた場合に非平面の杵を上杵にして製した 錠剤の方が，より大さな強度を示す傾向が認めら れた。これは圧縮圧が異なるためとも考えられる が，顆粒試料は圧縮時に顆粒の塑性変形および破 壊が起こり，粉末試料に比べて粒子の絡及合い構 造が生じやすいために，強度に及ぼす影響が大き く現われたと考えられる。そして粉末および顆粒 のいずれの試料を用いた場合も，非平面の杵を上 杵にして製した錠剤の方が，より均一な分割性を
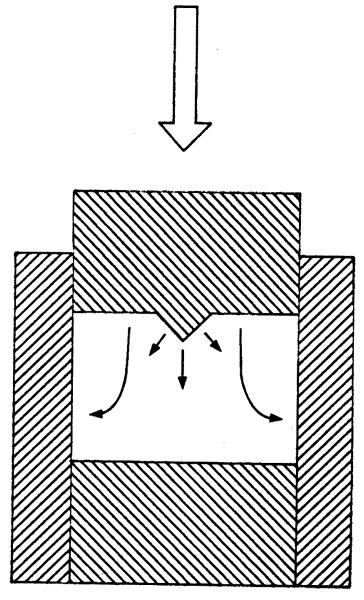

A-method
示す傾向が認められた.

これらの結果は錠剤の内部構造に相違を生じて いるためと推測される. 分割時の強度と分割重量 の変動との関連性より, 非平面の杵の位置によっ て圧縮圧の伝達傾向が異なっているものと思われ る. Aおよび B法の圧縮圧の伝達傾向の概念図を 示すと Fig. 6 のようになると考えられる.

矢印で示したようにA法による錠剤はB 法によ る錠剤よりも割線のある中央部に圧縮圧がより良 く伝達され，より均一な密度分布に近づく傾向に あると考えられる。粉末試料を用いた場合，分割 重量の変動において，B 法による錠剤は $\mathrm{A}$ 法に よる錠剤よりも用いた試料粉体の相違が大きく認 められた。このことは試料粉体の圧縮充填性の違 いであり，圧縮圧の伝達傾向の違いを裏付けるも のであると思われる. Table 1より粉末試料間で 定数 $1 / \mathrm{b}$ は大きな差は認められないが, 定数 $a$ よ り SL は流動性が最も悪く, パーフィラー『が最 も流動性が良いと思われる。また，前報5で報告 したよらに，SL はパーフィラー®および MCC の圧密過程と異なり, 凝集状態からの圧密過程を 示す. そのために SL は非平面の杵の位置が均一 な分割性に及ぼす影響が大きく現われ，パーフィ ラー®ではSLよりも小さくなったと考えられ る. そして MCC は圧縮時に比較的粒子移行が少 なく，圧力伝達性を均一化させることが報告され
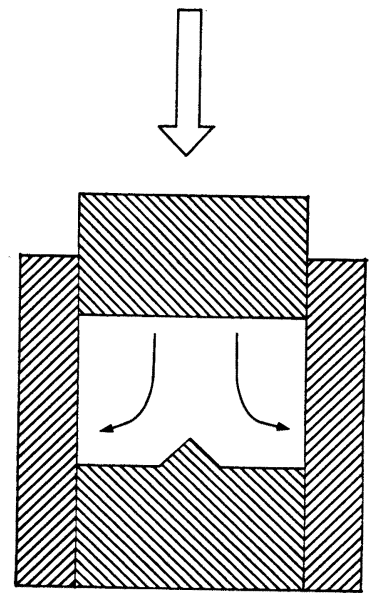

B-method

Fig. 6. Pressure Lines of Compaction Methods 
ている6). したがって, 均一な分割性は非平面の 杵の位置に影響されなかったと考えられる。

顆粒試料を用いた場合, 非平面の杵の位置によ って分割時の強度に差が認められた。このことは 錠剂の内部構造の相違を示しており, 非平面の杵 の位置によって圧縮圧の伝達傾向が異なることを 示唆していると考えられる. 顆粒試料は二次物性

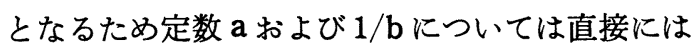
論じられないが， 1/b は顆粒の凝集力を示してい ると思われ，いずれの粒径においても顆粒の強度 は, 結合剤としてデンプン糊液を使用した顆粒の 方が若干大きいと推測される.そのため，デンプ ン糊液を用いた錠剤で非平面の杵の位置の影響が みられなかった場合があったと考えられる．顆粒 試料は粉末試料に比べて圧縮時に顆粒の塑性変形 および破壊が起こる可能性が高く, 錠剤の内部構
造は顆粒の塑性変形および破壊の程度によって左 右されると推測される，したがって圧縮圧の伝達 傾向の相違が，顆粒の強度などの物性と相まって 顆粒の塑性変形および破壊の程度に差を生じるこ とにより，均一な分割性に影響を及ぼしていると 考えられる。

\section{引用文献}

1）橋本健次, “粉体成形ハンドブック”, 日刊工業新 聞社, 1987, pp. 194-224.

2) 古屋 光, 粉体と工業, 8, 40-47 (1976).

3）川北公夫，インファケム， 2，8-14 (1981).

4) 伊東明彦, 小林由美子, 杉原正泰, 病院薬学, 15 . (1), 5-10 (1989).

5）伊東明彦, 荒木由美子, 杉原正泰, 病院薬学, 17 (4), 204-210 (1991).

6）アビセル時報総集篇 I, 旭化成，6-8（1983）. 